\title{
Comunicación

\section{Aproximaciones al campo académico de la comunicación en América Latina}

\author{
MAGDALENA SOFÍA PALÁU CARDONA ${ }^{1}$
}

La enseñanza de la comunicación, en América Latina como tal, tuvo su origen en la década de 1960. La investigación académica sobre la comunicación, realizada de forma más sistemática, empezó una década después. La investigación sobre los procesos de institucionalización de la enseñanza y la investigación de la comunicación datan de principios de la década de 1990. La inquietud de los investigadores de la comunicación, mexicanos y latinoamericanos, por investigar sobre el desarrollo de su propio campo de estudios está cumpliendo unos 15 años aproximadamente.

El origen de esta línea de trabajo, en México, se puede ubicar en dos hechos que consideramos como fundantes: el coloquio Hacia una Reconstrucción Reflexiva del Campo Académico de la Comunicación, celebrado en Guadalajara en 1993 y la publicación, en 1998, del libro La emergencia de un campo académico: continuidad utópica y estructuración cientifica de la investigación de la comunicación en México, de Raúl Fuentes.

1 Instituto Tecnológico y de Estudios Superiores de Occidente.

Correo electrónico: spalau@iteso.mx 
A lo largo de estos 15 años la reflexión sistemática sobre el campo académico de la comunicación en México ha generado una gran diversidad de productos que han aparecido publicados en diversas revistas académicas que circulan en nuestro país y en América Latina. Algunas de estas publicaciones centran su interés en la escala individual del proceso de institucionalización del campo; los más están interesados en la escala institucional, tanto en lo que se refiere al "subcampo educativo", es decir, en los procesos de institucionalización de la enseñanza, como en lo que se refiere al "subcampo científico", es decir, el proceso de institucionalización de la investigación en comunicación en nuestro país. Es en este ámbito del subcampo científico, referido a las instituciones y prácticas de investigación, en el que se inscribe el libro que aquí reseño.

El coordinador del libro colectivo Instituciones y redes académicas para el estudio de la comunicación en América Latina ha sido uno de los agentes más decisivos en el surgimiento y desarrollo de esta línea de investigación, que ha cobrado importancia en el trabajo reciente de la investigación de la comunicación en México y América Latina.

Raúl Fuentes ha estado directamente interesado, e involucrado, en el trabajo reflexivo del propio campo de la comunicación. Sus contribuciones iniciales a esta línea de investigación fueron una serie de sistematizaciones documentales sobre la investigación de la comunicación en México, que abarcan ya el largo periodo comprendido entre 1950 y 2001. Aunado a esto, Fuentes ha contribuido, a través de su participación en el diseño y la docencia en diversos programas de posgrado, a la formación de nuevos investigadores de la comunicación. Desde allí ha acompañado los procesos de formación de sujetos interesados en la investigación sobre el campo académico de la comunicación.

Fruto de este constante esfuerzo han aparecido, recientemente, dos publicaciones que recuperan los aportes centrales de las investigaciones realizadas en dichos procesos de formación. Una primera publicación apareció en el 2004 bajo el título Producción, circulación y reproducción académicas en el campo de la comunicación en México (Fuentes, 2004), y se centra tanto en el análisis de tres revistas académicas de circulación nacional como en el de tesis de maestría de tres universidades mexicanas. 
Instituciones y redes académicas para el estudio de la comunicación en América Latina, es un trabajo similar al anterior y en continuidad con el trabajo desarrollado por Fuentes a lo largo de muchos años, que amplía la mirada de lo nacional a lo regional y nos ayuda a construir una visión sobre el campo académico de la comunicación en América Latina.

El fundamento teórico que está en la base de esta línea de investigación es la construcción conceptual de los estudios de comunicación, sus agentes e instituciones, desde la perspectiva y el concepto de campo de Pierre Bourdieu. Desde allí se desmarca de las concepciones territoriales de campo, comprendido como área de estudio, para concebirlo como “"espacio' sociocultural de posiciones objetivas donde los agentes luchan por la apropiación del capital común" (Fuentes, 2005: 30).

Desde esa toma de posición inicial, Fuentes concibe el campo académico de la comunicación, homologable al campo científico de Bourdieu, constituido por tres subcampos: el de la producción de conocimiento o "subcampo de la investigación académica", el de la reproducción del conocimiento o "subcampo de la formación universitaria", y el de la aplicación del conocimiento o "subcampo de la profesión". El trabajo de Fuentes tiene su principal interés y desarrollo en el primero de estos subcampos, para el que define nueve procesos de estructuración en las escalas individual, institucional y sociocultural (Fuentes, 1998: 73)

Con lo anteriormente expuesto, podemos afirmar que dos de los aportes del trabajo de Raúl Fuentes para los estudios de comunicación en México son la constitución y consolidación de una línea de investigación que se propone una mirada autorreflexiva y crítica respecto del propio trabajo de investigación sobre la comunicación, y la construcción de modelos heurísticos que nos permiten acercarnos a este objeto de investigación.

Instituciones y redes académicas para el estudio de la comunicación en América Latina nos muestra los resultados de tres aproximaciones al proceso de institucionalización del campo académico de la comunicación en América Latina, en la escala institucional, y una reflexión sobre el sentido de los estudios de comunicación en la región.

La primera aproximación, construida por Gustavo León Duarte y que aparece bajo el título "La institucionalización del campo académico en América Latina”, pretende dar cuenta de la relación entre la situación 
sociohistórica de América Latina y el desarrollo e institucionalización del campo académico de la comunicación. Uno de sus principales aportes es recuperar, desde una perspectiva sociohistórica, el papel de la CIESPAL en el origen de los esfuerzos por hacer investigación de la comunicación en América Latina. Sin embargo, en su trabajo se alcanza a percibir una cierta confusión entre los que se constituyeron como centros de investigación y los que se conformaron como centros de documentación.

La segunda aproximación intenta construir una mirada que ayude a analizar las relaciones en el interior del campo académico. En el capítulo titulado "Las redes académicas", Ángela María Godoy Fajardo se propone articular la perspectiva de redes, cuyo origen es la sociología, con el análisis del campo académico de la comunicación en América Latina a partir del análisis de la revista Diá-logos de la Comunicación, publicación académica de la Federación Latinoamericana de Facultades de Comunicación Social. La aproximación que construye Godoy trabaja la conformación de redes en el plano de lo formal, y deja abierta la invitación al análisis de redes informales.

Por su parte Oscar Bustamante en el capítulo "Posgrados en comunicación en América Latina", hace un detallado análisis descriptivo de la oferta de posgrados en comunicación que se ofrecen en la región. Construye una mirada precisa y bien fundamentada empíricamente respecto de ese ámbito de la institucionalización del campo que ha sido poco abordada: los posgrados. Quizá uno de los principales límites de este trabajo es su carácter descriptivo y la carencia de una interpretación más explicativa de los interesantes resultados que se obtuvieron con este trabajo.

Estas tres aproximaciones a los procesos de estructuración del campo académico en América Latina, a través del acercamiento a los orígenes, a las redes y a los posgrados, nos permiten vislumbrar el reto que aún enfrentamos para consolidar un trabajo sistemático que nos permita reconocer los diversos factores implicados en el proceso de institucionalización del campo académico de la comunicación.

Por su parte Raúl Fuentes nos presenta, en el último capítulo, bajo el título "Para documentar las relecturas y reescrituras del campo", una recuperación histórica del sentido utópico de los estudios de comunicación en América Latina y la importancia de la documentación aca- 
démica como infraestructura para la investigación. Desde, allí, plantea que el campo académico de la comunicación en América Latina podrá avanzar en su legitimación y generar explicaciones que orienten las transformaciones sociales "mediante la formación universitaria de agentes académicos y profesionales competentes para producir socialmente sentido sobre la producción social de sentido." (p. 223) Devela, así, el sentido de su apuesta y de sus prácticas académicas: la formación de investigadores y la recuperación de información que haga accesible los resultados del trabajo de investigación.

Instituciones y redes académicas para el estudio de la comunicación en América Latina es un texto que, además de presentarnos importantes resultados respecto de la "investigación de la investigación" de la comunicación que se está realizando actualmente, nos permite confirmar que esta línea de investigación se está consolidando en México y América Latina a través de un trabajo sistemático, continuo y sustentado empíricamente. Con la lectura de trabajos como los presentados en este libro, vamos siendo testigos del proceso de maduración del propio campo, madurez que se manifiesta en la "creciente referencia a la propia historia" (p. 9), en la conciencia autocrítica del trabajo que realizamos y en la claridad respecto de los retos que hemos de enfrentar en el futuro.

\section{Bibliografía}

Fuentes Navarro, R. (1998) La emergencia de un campo académico: continuidad utópica y estructuración científica de la investigación de la comunicación en México, Zapopan: ITESO / UdeG.

- (coord.) (2004) Producción, circulación y reproducción académicas en el campo de la comunicación en México, Zapopan: ITESO.

- (2005) "El campo académico de la comunicación en México como objeto de análisis auto-reflexivo", en Lozano, J.C. (ed.) La comunicación en México: Diagnóstico, balances y retos, México: CONEICC / ITESM. 
